\title{
RELEVANSI KURIKULUM FAKULTAS PSIKOLOGI UIN SUNAN GUNUNG DJATI BANDUNG DENGAN DUNIA KERJA
}

\author{
Mursidin, Ulfiah, \& Ening Ningsih \\ Fakultas Psikologi UIN Sunan Gunung Djati Bandung
}

Curriculum is one of the important components in education which has a big role in determining the direction and purpose that will be reached by the academic institution. Therefore, curriculum must be designed on the basis of curriculum development principles should be noticed. One of the principles is the curriculum relevance with the employment. So, to evaluate the curriculum, including psychology faculty UIN SGD Bandung, it can be conducted by scrutinizing how far the curriculum relevance with occupation.

To scrutinize how far the curriculum relevance with occupation, we can trace from alumni's feed back. So, in this research it has been scrutinized how curriculum relevance of psychology faculty UIN SGD Bandung with the occupation taken from alumni's view, the job appropriateness with the competence and psychology profession, and the hope of alumni to curriculum change.

The data of research are processed either qualitative approach or quantitative by descriptive statistic analyzing present age calculation, and level category and also the analysis of contingency coefficient correlation test. From the result of data processing, it shows that most of alumni view that the curriculum of psychology faculty UIN SGD Bandung is still relevant with occupation. It is strengthened by the data showing the most of alumni's job which generally is still appropriate with the psychology profession scope. It is so with being relatively fast for the alumni to get the job after graduating. It indicates that the products (graduations) of psychology faculty UIN SGD Bandung still have any competition and they are needed by the user.

From correlation test result, it can be concluded that there is no respondent's characteristic which has significant relation with their view to the curriculum relevance of psychology faculty UIN $S G D$ Bandung with occupation. In other word, respondent's characteristic can't be a significant correlation to human's view in curriculum.

Although Alumni view curriculum still relevant with occupation, but all respondents still hope any change in curriculum to be more applicative and relevant with human's need especially for occupation.

Keywords: Curriculum, work

\section{Latar Belakang}

Keyakinan bahwa pendidikan merupakan wahana ampuh untuk membawa bangsa dan negara menjadi maju dan terpandang dalam pergaulan bangsa-bangsa di dunia internasional, boleh dikatakan tidak ada keraguan lagi. John Naisbit dan Patricia

\begin{abstract}
Aburdence, melalui "Megatrend 2000", mengatakan: "Tepi Asia Pasifik telah memperlihatkan negara miskinpun bangkit, meskipun tanpa sumber daya alam melimpah, asalkan negara melakukan investasi yang cukup dalam hal sumber daya manusia". Maka mengkaji pendidikan sebagai praksis
\end{abstract}


pembangunan bangsa tetap menarik dan penuh makna. Lebih-lebih di tengah suasana krisis multi dimensional yang berkepanjangan, dimana peran pendidikan ikut dipertanyakan, bahkan digugat.

Keberhasilan upaya peningkatan mutu pendidikan sangat dipengaruhi oleh kualitas sumberdaya manusia (SDM) yang terlibat didalamnya, karena dalam sistem pendidikan apapun, kualitas kemampuan dan profesionalisme dari the man behind the gunnya merupakan kunci keberhasilan sistem pendidikan. Secara praktis, peningkatan mutu pendidikan merupakan suatu proses yang sinergik dengan upaya peningkatan sumber daya manusia.

Upaya peningkatan kualitas output pendidikan ke arah pendidikan yang profesional yang dapat menghasilkan kualitas SDM yang unggul hanya mungkin dapat dilakukan melalui peningkatan mutu pendidikan baik dalam skala lokal maupun nasi-onal. Namun, saat ini pendidikan nasional masih menghadapi persoalan, terutama yang berkaitan dengan kualitas, relevansi, dan efisiensi. Oleh karena itu, lembaga pendidikan tinggi diharapkan mampu memberikan respons terhadap kebutuhan tersebut.

Salah satu cara lembaga pendidikan tinggi dalam meningkatkan mutu pendidikan agar dapat menghasilkan output yang sesuai dengan kebutuhan masyarakat adalah melalui pene-tapan kurikulum yang memadai dan tepat sasaran. Kurikulum merupakan alat yang sangat penting dan ikut menentukan keberhasilan pendidikan karena tanpa adanya kurikulum yang baik dan tepat maka akan sulit dalam mencapai tujuan dan sasaran pendidikan yang dicita-citakan.

Dinamika dan tuntutan kebutuhan masyarakat yang senantiasa berkembang bahkan berubah dari waktu ke waktu menuntut respons yang penuh pertimbangan dari para pengelola institusi pendidikan, baik dalam perencanaan, penyelenggaraan, maupun pengawasannya, termasuk dalam mengevaluasi kurikulumnya, agar senantiasa up to date dalam menjawab kebutuhan masyarakat. Untuk keperluan itu, maka penting bagi institusi penyelenggara pendidikan untuk mendapatkan feedback dari berbagai kalangan, khususnya dari para pengguna lulusan dan para alumninya, yang menjadi subjek sekaligus objek pendidikan.

Sebagai bagian dari organ penyelenggara pendidikan di lingkungan Universitas Islam Negeri Sunan Gunung Djati Bandung yang relatif masih baru, Fakultas Psikologi tentunya dihadapkan pada berbagai kendala sekaligus tantangan dalam menyelenggarakan program studi psikologi di UIN SGD Bandung. Salah satu tantang- annya adalah bagaimana Fakultas Psikologi UIN SGD Bandung dapat meramu kurikulum yang tidak hanya sesuai dengan tujuan pendidikan nasional, tujuan pendidikan tinggi psikologi Indonesia, serta visi dan misi UIN SGD Bandung, tetapi juga mampu menjawab kebutuhan masyarakat, terutama tuntutan dunia pekerjaan yang semakin kompleks dan terdiferensiasi.

Untuk menghadapi tantangan tersebut maka tim penyusun kurikulum Program Studi 
Psikologi UIN SGD Bandung, sejak masih embrio dan menjadi bagian dari Fakultas Tarbiyah sejak tahun 1998 telah melakukan studi banding ke berbagai perguruan tinggi negeri maupun swasta serta menghadiri berbagai seminar, lokakarya, dan terutama kolokium nasional psikologi, untuk mendapatkan masukan dan memiliki dasar pijakan yang kokoh dalam menata kurikulum program studi psikologi di UIN SGD Bandung.

Berdasarkan telaahan hasil studi banding, hasil-hasil kolokium nasional psikologi, dan seiring dengan perubahan arah kebijakan pendidikan nasional serta berubahnya status Jurusan Psikologi menjadi Fakultas Psikologi UIN SGD Bandung, kurikulumnya telah mengalami beberapa kali revisi. Namun yang terjadi tampaknya masih lebih berorientasi kepada tuntutan penyesuaian terhadap arah kebijakan pendidikan nasional maupun institusi dari pada hasil evaluasi terhadap komponen-komponen kurikulum secara menyeluruh. Dengan demikian, perlu dipertanyakan apakah kurikulum Fakultas Psikologi UIN SGD Bandung telah memenuhi standar ideal pendidikan tinggi psikologi terutama dalam memenuhi tuntutan dunia kerja?

Salah satu cara untuk mendapatkan data yang bisa dijadikan landasan dalam mengevaluasi kurikulum tersebut adalah melalui penelitian.

\section{Manfaat dan Tujuan Penelitian}

Hasil penelitian ini diharapkan berguna untuk memperkaya khasanah literatur, dapat menstimulasi atau menjadi bahan referensi bagi penelitian-penelitian lainnya, dan juga diharapkan dapat menjadi bahan masukan bagi perumusan kurikulum serta arah kebijakan penyelenggaraan pendidikan psikologi, khususnya di Fakultas Psikologi UIN SGD Bandung.

Penelitian ini bertujuan untuk:

1) Menggambarkan rumusan kurikulum Fakultas Psikologi UIN SGD Bandung.

2) Mengetahui pandangan alumni terhadap relevansi kurikulum Fakultas Psikologi UIN SGD Bandung dengan dunia kerja.

3) Mengetahui kesesuaian antara bidang pekerjaan alumni dengan kompetensi dan profesi psikologi.

4) Mengetahui harapan alumni terhadap perubahan kurikulum Fakultas Psikologi UIN SGD Bandung.

\section{Kerangka Berpikir}

Pendidikan merupakan salah satu pondasi utama dalam rangka menciptakan sumber daya insani yang berkualitas. Melalui pendidikan, pengerahan potensi bangsa yang melimpah untuk mewujudkan kesejahteraan bangsa yang sebesar-besarnya akan lebih terarah dan optimal sehingga keanekaragam sumber daya, kompetensi, dan budaya yang dimiliki bangsa ini seharusnya dapat memberikan kontribusi yang maksimal bagi pembangunan bangsa dan negara. Oleh karena itu, keberhasilan dalam membangun pilar pendidikan yang kokoh seringkali menjadi landasan dan tolak ukur bagi tegaknya pilarpilar kehidupan yang lainnya. 
Demi terciptanya sistem pendidikan yang unggul dan berkualitas, tentunya diperlukan sejumlah faktor atau komponen pendidikan yang saling terkait. Salah satu faktor yang memiliki kedudukan sentral dalam proses pendidikan adalah kurikulum.

Pendidikan dan kurikulum adalah dua hal yang tidak dapat di dipisahkan. Kurikulum merupakan alat untuk mencapai tujuan pendidikan. Kurikulum juga merupakan suatu rencana pendidikan, memberikan pedoman dan pegangan tentang jenis, lingkup, urutan isi, dan proses pendidikan. Seperti dikemukakan Mauritz Johnson (1967, dalam Sukmadinata, 2008) kurikulum "prescribes (or at least anticipates) the result of instruction". Dengan kata lain, kurikulum mengarahkan segala bentuk aktivitas pendidikan demi tercapainya tujuan-tujuan pendidikan, baik berkenaan dengan penguasaan pengetahuan, pengembangan pribadi, kemampuan sosial, atau kemampuan bekerja.

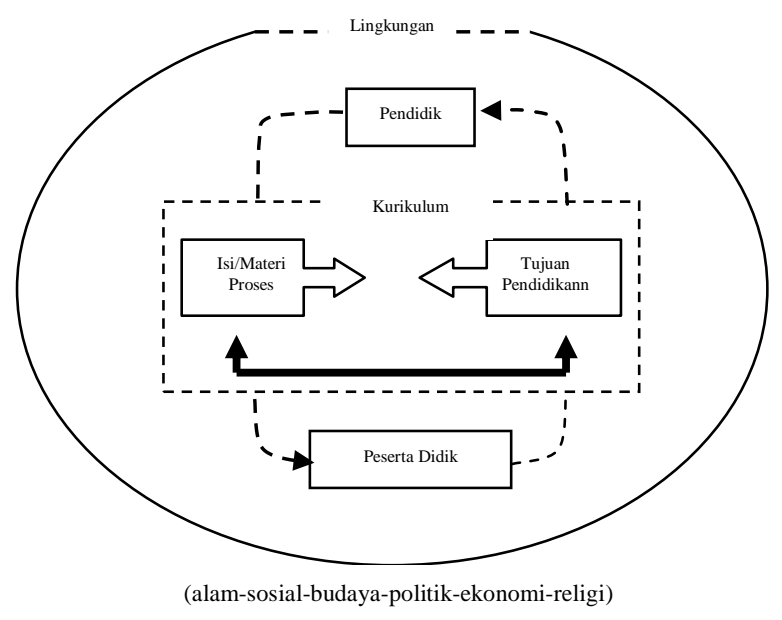

Gambar 1. Komponen-Komponen Utama Pendidikan (Diadaptasi dari Sukmadinata, 2008:3)

Untuk mengembangkan kemampuankemampuan tersebut diperlukan metode penyampaian dan alat bantu atau media yang memadai. Untuk menilai hasil dan proses pendidikan juga diperlukan cara-cara dan alat penilaian tertentu pula. Empat komponen utama kurikulum yaitu tujuan, bahan ajar atau isi/materi, metode dan alat/media, serta penilaian/evaluasi. Ini dapat dilihat pada gambar 1.

Untuk menghasilkan suatu rumusan kurikulum yang baik maka diperlukan suatu desain kurikulum yang didasarkan pada asasasas dan prinsip-prinsip pengembangan kurikulum yang memadai. Menurut David Pratt (1980, dalam Sanjaya, 2008) desain adalah proses yang disengaja tentang suatu pemikiran, perencanaan, dan penyeleksian bagian-bagian, teknik dan prosedur yang mengatur suatu tujuan atau usaha. Atas dasar itu, maka pengembangan kurikulum (curiculum development atau curiculum planning) adalah proses atau kegiatan yang disengaja dan dipikirkan untuk menghasilkan sebuah kurikulum sebagai pedoman dalam proses dan penyelenggaraan pendidikan.

Sementara Seller dan Miller (19-85, dalam Sanjaya, 2008) mengemukakan bahwa proses pengembangan kurikulum adalah rangkaian kegiatan yang dilakukan terusmenerus. Seller memandang bahwa pengembangan kurikulum harus dimulai dari menentukan orientasi kurikulum, yakni kebijakan-kebijakan umum, misalnya arah dan tujuan pendidikan, pandangan tentang hakikat belajar dan anak didik, pandangan tentang keberhasilan implementasi kurikulum, dan sebagainya. Berdasarkan orientasi itu 
selanjutnya dikembangkan kurikulum, kemudian diimplementasikan dalam proses belajar, dan dievaluasi. Hasil dari evaluasi itulah yang dijadikan bahan dalam menentukan orientasi. Demikian seterusnya hingga membentuk siklus.

Untuk lebih memahami proses pengembangan kurikulum mari perhatikan pendapat Zais dalam bukunya Curriculum: Principle and Foundations (1976). Menurut Zais pengembangan kurikulum harus dimulai dengan asumsi-asumsi filosofis sebagai sistem nilai atau pandangan hidup suatu bangsa. Berdasarkan asas filosofi tersebut selanjutnya ditentukan tentang hakikat pengetahuan (epistemology/the nature of knowledge), sosiokultural, hakikat anak didik, dan teoriteori belajar. Dengan kata lain landasan pengembangan kurikulum meliputi asas: filosofi, psikologis, dan sosial budaya, termasuk di dalamnya asas teknologis. Zais menggambarkan proses pengembangan kurikulum seperti terlihat pada gambar 2.

Selain harus memperhatikan asas-asas pengembangan kurikulum, agar suatu kurikulum dapat berfungsi sebagai pedoman, maka ada sejumlah prinsip yang harus diperhatikan dalam proses pengembangan kurikulum. Prinsip-prinsip tersebut antara lain prinsip : relevansi, fleksibilitas, konti-nuitas, kepraktisan, efektivitas, dan efisiensi.

Salah satu prinsip penting yang akan dibahas dan terkait dengan penelitian ini adalah prinsip relevansi, yaitu sejauhmana kesesuaian atau keserasian antar komponenkomponen dalam kurikulum itu sendiri maupun antara komponen-komponen kurikulum dengan nilai-nilai dan kebutuhan yang ada di masyarakat sehingga dapat membekali siswa dengan pengetahuan, sikap, dan keterampilan yang sesuai dengan tuntutan dan harapan masyarakat. Relevansi internal (di dalam kurikulum itu sendiri) berkaitan dengan konsistensi dan kesesuaian antara komponen-komponennya, yaitu kesesuaian antara tujuan yang ingin dicapai, isi/materi/pengalaman belajar yang harus diberikan kepada siswa, strategi atau metode yang digunakan, serta alat penilaian untuk melihat ketercapaian tujuan. Sementara relevansi ekternal berkaitan dengan keserasian antara tujuan, isi, dan proses belajar yang tercakup dalam kurikulum dengan tuntutan, kebutuhan, dan perkembangan masyarakat, yang dapat dilihat dari tiga hal:

1) Relevansi kurikulum dengan lingkungan kehidupan peserta didik. Artinya, proses pengembangan kurikulum dan menetapkan isi/bahan ajar hendaknya disesuaikan dengan kondisi lingkungan dan kehidupan nyata di sekitar peserta didik.

2) Relevansi kurikulum dengan perkembangan zaman, baik kehidupan sekarang maupun kehidupan yang akan datang.

3) Relevansi kurikulum dengan tuntutan dunia kerja. Artinya, kurikulum harus mampu memenuhi kebutuhan dunia kerja yang semakin berkembang dan terdifferensiasi sesuai bidangnya masingmasing (Sukmadinata, 2008; Sanjaya, 2008). 


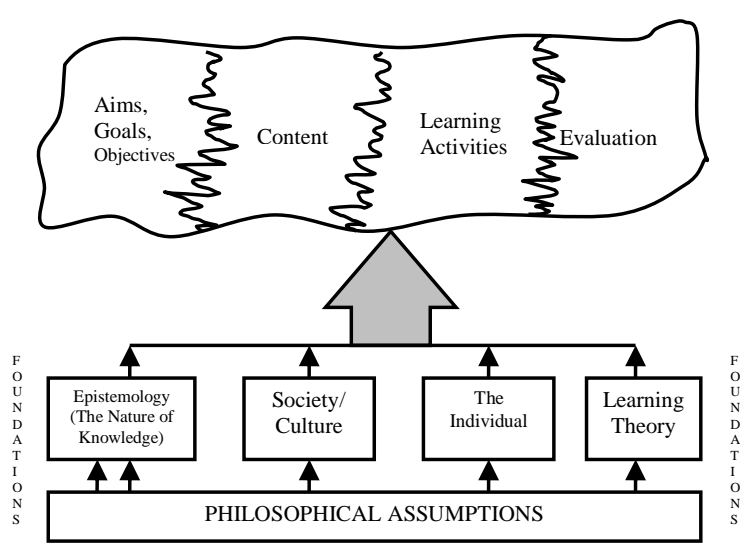

Gambar 2. Model Kurikulum Menurut Zais

(Diadaptasi dari Zais, 1976:97)

Pendidikan dapat dipandang sebagai invested of man power resources. Untuk menghasilkan lulusan pendidikan yang memiliki nilai relevansi dengan dunia kerja diperlukan kurikulum yang dapat mengantisipasi apa yang akan dihadapi peserta didik di dunia kerja. Apabila kualifikasi lulusan suatu lembaga pendidikan sesuai dengan tuntutan masyarakat maka lulusan (hasil pendidikan) tersebut memiliki nilai relevansi yang tinggi. Sebaliknya, kurang relevannya komponen-komponen kurikulum dengan kebutuhan masyarakat mengakibatkan sukarnya lulusan dalam menghadapi tuntutan dunia kerja.

Untuk melihat relevan-tidaknya suatu kurikulum program studi perguruan tinggi, termasuk di Fakultas Psikologi UIN SGD Bandung, dengan kebutuhan masyarakat, khususnya dunia kerja, dapat dilihat antara lain dari kategori lulusannya berdasarkan hasil evaluasi atau umpan balik (feedback) yang diterima dari masyarakat masyarakat pengguna lulusan atau pengguna jasa psikologi (user) maupun alumni sendiri sebagai subjek yang mengalami dampak langsung maupun tidak, dari kurikulum yang diterapkan. Juga masukan para alumni atas pelaksanaan dan dampak program pendidikan yang mereka alami, terutama di dunia kerja. Kerangka pemikiran tersebut secara skematis dapat dilihat pada gambar 3.

\section{Rumusan Permasalahan}

Seperti telah dikemukakan bahwa untuk menentukan keberhasilan suatu sistem pendidikan, khususnya kurikulum pendidikan, banyak aspek yang harus dievaluasi. Salah satunya adalah selain dari kategori produk/ lulusan juga bisa dari sejauhmana kurikulum yang dikembangkan sudah memenuhi prinsip relevansi, baik relevansi internal maupun eksternal. Hal ini seperti telah ditegaskan dalam Undang-Undang Nomor 20 Tahun 2003 Bab X 36 ayat 3 tentang Sistem Pendidikan Nasional mengenai kurikulum disusun sesuai dengan jenjang pendidikan dalam kerangka Negara Kesatuan Republik Indonesia dengan memperhatikan salah satunya adalah tuntutan dunia kerja.

Untuk itu diajukan beberapa per tanyaan berikut:

1) Bagaimana rumusan kurikulum Fakultas Psikologi UIN SGD Bandung?

2) Bagaimana pandangan alumni terhadap relevansi kurikulum Fakultas Psikologi UIN SGD Bandung dengan dunia kerja?

3) Adakah kesesuaian antara bidang pekerjaan alumni dengan kompetensi dan profesi psikologi? 
4) Bagaimana harapan alumni terhadap perubahan kurikulum Fakultas Psikologi UIN

SGD Bandung?

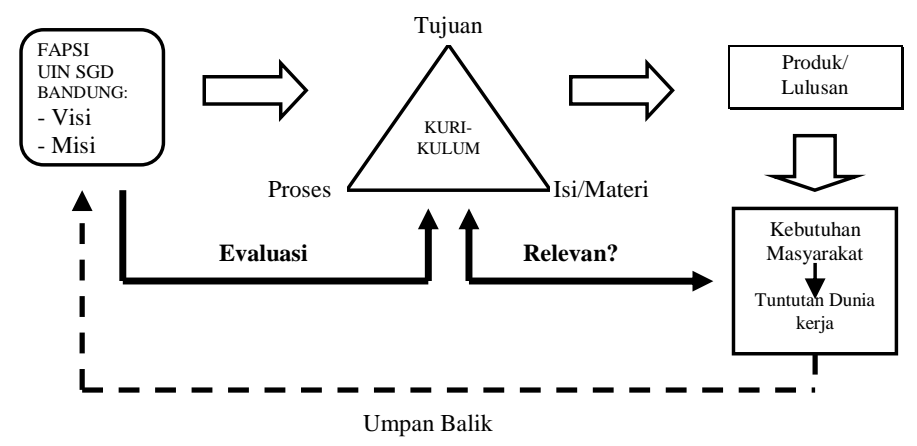

Gambar 3. Skema Kerangka Pemikiran Relevansi Kurikulum dengan Dunia Kerja

\section{Metode Penelitian}

Penelitian ini tergolong pada penelitian deskriptif (descriptive research). Seperti dikemukakan oleh Kumar (1996:9),

"A study classified as descriptive research attempts to describe systematically a situation, problem, phenomenon, service or program, or provides information about, say, the living conditions of a community, or describes attitudes towards an issue".

Variabel utama penelitian ini adalah relevansi kurikulum Fakultas Psikologi UIN SGD Bandung dengan dunia kerja. Mengacu pada beberapa literatur, komponen-komponen kurikulum yang harus dilihat relevansinya tersebut meliputi:

- Komponen tujuan, yaitu arah atau sasaran yang diharapkan oleh suatu ku-rikulum, dalam hal ini kesesuaian kurikulum Fakultas Psikologi UIN SGD Bandung dengan dunia kerja.

- Komponen isi/ materi, yaitu relevan tidaknya isi/ materi kurikulum
Fakultas Psikologi UIN SGD Bandung tuntutan dunia kerja.

- Komponen proses / strategi, yaitu relevansi sistem penyampaian dan media proses pembelajaran di Fakultas Psikologi UIN SGD Bandung dengan tuntutan dunia kerja.

Sebagai hasil tambahan dilakukan juga uji korelasi terhadap beberapa variabel karakteristik responden yang diduga terkait dengan pandangan alumni terhadap relevansi kurikulum Fakultas Psikologi UIN SGD Bandung dengan dunia kerja. Variabel penunjang tersebut antara lain jenis kelamin, usia, status marital, tahun masuk dan lulus kuliah, yudisium, asal sekolah menengah, pendidikan terakhir, perkerjaan, waktu yang diperlukan untuk mendapatkan pekerjaan, penghasilan alumni, serta beberapa pandangan umum dan harapan alumni terhadap perubahan kurikulum Fakultas Psikologi UIN SGD Bandung. Maka dalam penelitian ini digunakan juga metode korelasional (correlational research).

Tabel 1.

Alumni/ Lulusan Fakultas Psikologi UIN SGD Tahun 2006-2008

\begin{tabular}{|c|c|}
\hline Tahun & Jumlah Lulusan \\
\hline 2006 & 26 \\
\hline 2007 & 34 \\
\hline 2008 & 51 \\
\hline
\end{tabular}

Sumber: Fakultas Psikologi UIN SGD Bandung (2008) 
Secara operasional variabel-variabel tersebut akan digali melalui kuesioner berupa Skala Relevansi Kurikulum dengan Dunia Kerja dan Angket Data Penunjang untuk menggali beberapa karakteristik dan pandangan umum serta saran atau harapan alumni terhadap kurikulum yang dapat dijadikan sebagai data penunjang. Berdasarkan skor skala tersebut maka pandangan alumni terhadap relevan tidaknya kurikulum dengan dunia kerja akan dibagi dalam lima kategori, yaitu bila skor subjek $x$ :

- $x \leq 60$, kurikulum sangat tidak relevan dengan dunia kerja.

- $60<x \leq 80$, kurikulum tidak relevan dengan dunia kerja.

- $80<x \leq 100$, kurikulum cukup relevan dengan dunia kerja.

- $100<x \leq 120$, kurikulum relevan dengan dunia kerja.

- $120<x$, kurikulum sangat relevan dengan dunia kerja.

\section{Partisipan}

Karakteristik subjek yang diperlukan dalam penelitian ini adalah semua alumni Program Studi/ Fakultas Psikologi UIN SGD Bandung. Sayangnya sebaran populasi sulit diketahui secara cermat karena belum adanya daftar administratif (terutama alamat tempat tinggal dan tempat bekerja) alumni yang lengkap. Dari pihak Fakultas Psikologi hanya diperoleh data jumlah mahasiswa per angkatan dan jumlah lulusan dari tahun 2006-2008 seperti terlihat pada tabel 1 . Oleh karena itu, penentuan sampel dalam penelitian ini dilakukan secara nonrandom sampling atau nonprobability sampling. Artinya, penentuan subjek tidak dilakukan secara acak pada semua alumni melainkan secara aksidental dengan teknik snow ball yaitu pengambilan data dan informasi tentang keberadaan alumni diketahui dari alumni lain yang berhasil ditemui, sampai akhirnya diperoleh sebanyak 31 subjek sebagai sampel penelitian.

Untuk studi pendahuluan guna mendapatkan data tentang berbagai kebijakan teknis Pendidikan Tinggi Psikologi baik pada level nasional maupun level satuan penyelenggara pendidikan (Fakultas Psikologi UIN) dan menggali perkembangan rumusan kurikulum Fakultas Psikologi UIN SGD Bandung maka digunakan metode studi literatur dan dokumentasi. Sementara data utama dalam penelitian ini akan digali dengan instrumen atau alat pengumpul data berupa kuesioner yang terdiri dari dua bagian: bagian pertama berupa Skala Relevansi Kurikulum dengan Dunia Kerja sedangkan bagian kedua berupa Angket Data Penunjang.

\section{Skala Relevansi Kurikulum dengan}

Dunia Kerja digunakan untuk menggali data utama berupa pandangan alumni terhadap relevansi kurikulum Fakultas Psikologi UIN SGD Bandung dengan dunia kerja yang terdiri dari 30 item. Skala ini disusun berdasarkan model Skala Likert dengan lima alternatif jawaban, yaitu Sangat Setuju (SS), Setuju (S) ,Tidak dapat Menentukan Setuju atau Tidak (E), Tidak Setuju (TS), dan Sangat Tidak Setuju (STS). Untuk menghindari stereotipe jawaban, sebagian item dibuat dalam arah positif atau 
favorabel (favourable) dan sebagian lagi dalam arah negatif atau tidak favorabel (unfavourable). Untuk setiap item unfavourable masing-masing jawaban diberi skor sebagai berikut: $\mathrm{SS}=1, \mathrm{~S}=2, \mathrm{E}=3$, TS $=4$, dan STS $=5$, sedangkan untuk item favourable urutan penskoran dibalik menjadi $\mathrm{SS}=5, \mathrm{~S}=4, \mathrm{E}=3, \mathrm{TS}=2$, dan $\mathrm{STS}=1$. Dengan demikian, Skala Relevansi Kurikulum dengan Dunia Kerja memiliki rentang skor antara 30-150. Artinya adalah semakin tinggi skor menunjukkan semakin relevan kurikulum dengan dunia kerja dipandang oleh alumni, dan sebaliknya semakin rendah skor menunjukkan semakin tidak relevan kurikulum dengan dunia kerja dipandang oleh alumni. Untuk memudahkan dalam klasifikasi, dibuat juga kategorisasi jenjang.

\section{Angket Data Penunjang digunakan} untuk menggali data penunjang berupa karakteristik responden dan pandangan umum serta saran atau harapan alumni terhadap kurikulum Fakultas Psikologi UIN SGD Bandung yang terdiri dari 20 item. Sebanyak 16 item dibuat dalam bentuk pilihan ganda sehingga subjek tinggal memilih dengan memberikan tanda silang (x) pada pilihan yang sesuai dengan keadaan dirinya, sedangkan 3 item lagi berkaitan dengan pandangan dan harapan alumni terhadap perubahan kurikulum dibuat dalam bentuk terbuka (open form questionnaire) untuk memberi kesempatan kepada subjek menyatakan pendapatnya sehingga diperoleh masukan yang seluasluasnya bagi per-baikan kurikulum Fakultas Psikologi UIN SGD Bandung ke depan.

\section{Uji Coba Alat Ukur}

Sebelum alat ukur atau pengumpul data digunakan terlebih dahulu dilakukan uji coba (try out) kepada sejumlah responden yang memenuhi karakteristik subjek penelitian. Hal ini dimaksudkan untuk uji coba keterbacaan (face validity) dan mendapatkan persyaratan psikometris melalui analisis item, uji reliabilitas, dan uji validitas, sehingga diperoleh alat ukur yang reliabel dan valid.

\section{Analisis Item}

Analisis item merupakan proses pengujian parameter-parameter item guna mengetahui apakah item memenuhi persyaratan psikometris untuk disertakan sebagai bagian dari skala atau tidak. Prosedurnya meliputi dua tahap, yaitu tahap evaluasi kualitatif dan kuantitatif. Tahap evaluasi kualitatif dilakukan untuk melihat apakah itemitem yang ditulis sudah sesuai dengan: kisi-kisi (blue-print) dan indikator atribut yang hendak diung-kap, kaidah penulisan yang benar, dan mengandung social desirability yang tinggi atau tidak. Tahap ini dilakukan dengan meminta masukan kepada ahli dalam pengukuran (psikometri) dan ahli dalam masalah atribut yang hendak diukur. Setelah tahap evaluasi kualitatif dilakukan, kumpulan item yang sudah dikompilasi ulang selanjutnya diujicobakan kepada sejumlah subjek yang karakteristiknya setara dengan subjek penelitian untuk melaksanakan tahap evaluasi kedua yaitu analisis kuantitatif terhadap parameter-parameter item.

Untuk skala psikologi yang mengukur atribut afektif, dalam seleksi item parameter yang paling penting adalah daya beda atau daya 
diskriminasi item, yaitu sejauhmana item mampu membedakan antara individu atau kelompok yang memiliki dan tidak memiliki atribut yang diukur. Indeks daya beda ini juga merupakan indikator keselarasan atau konsistensi antara fungsi item dengan fungsi skala secara keseluruhan yang dikenal dengan istilah korelasi item-total (itemtotal correlation $=\mathrm{r}_{\mathrm{i} x}$ ) yang disebut pula dengan parameter daya beda item. Formulasi korelasi yang digunakan dalam komputasi bergantung kepada sifat penskalaan (Azwar, 2003; Djatmika, 1998: 14; Friedenberg, 1995: 277).

Meskipun menggunakan skala model Likert, namun peneliti tidak melakukan pembobotan nilai bagi stimulus ataupun respons skala sehingga level skala dianggap ordinal. Maka untuk menentukan indeks korelasi itemtotal digunakan formula Spearman's Rank-Order Corre- lation Coefficient (Siegel, 1997: 250-257), yaitu

$$
r_{s}=1-\frac{6 \sum_{i=1}^{N} d_{i}^{2}}{N^{3}-N}
$$

Jika proporsi angka-sama pada kedua variabel besar, maka digunakan per-samaan (2) yaitu

$$
r_{s}=\frac{\sum x^{2}+\sum y^{2}-\sum d_{i}^{2}}{2 \sqrt{\sum x^{2} \sum y^{2}}}
$$

dimana:

$d_{i}$ : selisih antara dua ranking

$N$ : jumlah responden

$$
\begin{aligned}
& \sum x^{2}=\frac{N^{3}-N}{12}-\sum T_{x} \\
& \sum y^{2}=\frac{N^{3}-N}{12}-\sum T_{y}
\end{aligned}
$$

dengan $T=\frac{t^{3}-t}{12}$

$x$ dan $y$ : variabel-variabel yang akan di korelasikan

$\mathrm{t}$ : banyak observasi yang berangka sama pada suatu ranking tertentu

Adapun langkah-langkahnya adalah sebagai berikut:

a. Mendaftar subyek dan skor-skor variabel yang akan dicari indeks korelasinya.

b. Memberi ranking untuk setiap subyek pada masing-masing variabel yang akan dicari indeks korelasinya.

c. Menentukan selisih (harga $d_{i}$ ) untuk setiap subyek dengan mengurangkan ranking variabel yang satu dengan ranking variabel yang lainnya.

d. Menguadratkan harga $d_{i}$ setiap sub- yek untuk mendapatkan harga $d_{i}^{2}$ kemudian harga-harga $d_{i}^{2}$ tersebut dijumlahkan.

e. Menentukan indeks korelasi $r_{s}$ dengan rumus 1, namun jika proporsi angka-sama pada variabel besar, maka gunakan rumus 2 dengan terlebih dahulu menentukan nilai $\Sigma x^{2}$ dan $\Sigma y^{2}$.

Penghitungan dibantu dengan program SPSS 11.5 for Windows mengikuti alur Analyze $\rightarrow$ Correlate $\rightarrow$ Bivariate $\rightarrow$ Spearman

Nilai $r_{s}$ yang diperoleh dari perhitungan ini menunjukkan nilai daya beda item. Secara teoretis, makin tinggi koefisien korelasi positif antara skor item dengan skor skala, berarti makin baik ke-sesuaian antara item dengan keseluruhan skala. Sebagai kriteria pemilihan item, nilai daya beda item yang nilainya positif 
pada prinsipnya dapat digunakan, tetapi pada umumnya item yang memiliki indeks daya beda lebih dari atau sama de-ngan $0,3 \quad\left(\mathrm{r}_{\mathrm{ix}} \geq 0,3\right)$ dianggap memuaskan. Namun bila item yang lolos tidak mencukupi jumlah item yang diharapkan, peneliti dapat menurunkan batas kriteria (Azwar, 2002: 65; Friedenberg, 1995: 273).

Hasil perhitungan dengan program SPSS 11.5 for Windows, pada Skala Relevansi Kurikulum dengan Dunia Kerja terdapat empat item yaitu nomor 15, 17, 18, dan 25 yang memiliki indeks koefisien korelasi positif namun kurang dari 0,3. Akan tetapi, peneliti tetap memakai keempat item tersebut setelah dilakukan revisi bahasa. Dengan demikian, semua item yang berjumlah 30 digunakan dalam alat ukur.

\section{Uji Reliabilitas}

Reliabilitas berarti keterpercayaan, kecermatan, atau konsistensi hasil pengukuran dari waktu ke waktu. Dalam pelaksanaannya reliabilitas dinyatakan oleh koefisien reliabilitas $\left(\mathrm{r}_{\mathrm{xx}}\right)$ yang angkanya berada pada rentang 0-1. Semakin mendekati 1 berarti semakin tinggi reliabilitas alat ukur.

Data untuk menghitung koefisien reliabilitas diperoleh dari hasil penyajian satu set skala yang dikenakan hanya sekali saja pada sekelompok responden saat uji coba. Oleh karena itu, metode pengujian reliabilitas yang digunakan adalah metoda Split-half Reliability, yaitu nilai reliabilitas skala ditentukan dengan mencari indeks korelasi antara variabel jumlah skor tiap individu pada item-item ganjil dan variabel jumlah skor tiap individu pada item-item genap. Untuk menentukan indeks korelasi ini karena level skalanya ordinal maka digunakan Rank-Order Correlation Coefficient dari Spearman dengan rumus dan langkah-langkah seperti penentuan indeks korelasi pada analisis item. Indeks korelasi Split-half ini dikoreksi dengan rumus Spearman-Brown Prophesy berikut:

$$
r_{b}=\frac{(N)\left(r_{l}\right)}{1+(N-1)\left(r_{l}\right)}
$$

dimana

$N=2$

$r_{b}$ : indeks korelasi hasil koreksi

$r_{l}$ : indeks korelasi Rank-Spearman

Dari hasil perhitungan program SPSS 11.5 for Windows dan setelah dikoreksi dengan Spearman-Brown Prophesy diketahui bahwa Skala Relevansi Kuri-kulum dengan Dunia Kerja memiliki koefisien reliabilitas sebesar 0.874. Ini menunjukkan korelasi yang tinggi dan skala dianggap reliabel atau memiliki reliabilitas yang cukup baik.

\section{Uji Validitas}

Pengujian validitas alat ukur diperlukan guna mengetahui apakah alat ukur, dalam penelitian ini berupa skala, mampu menghasilkan data yang akurat sesuai dengan tujuan ukurnya atau tidak. Karena hanya didapatkan satu set skor, maka untuk menguji validitas skala di-gunakan prosedur pengujian validitas konstruk dengan mencari indeks korelasi antara skor masingmasing faktor atau as-pek skala dengan skor total skala (Djat-mika, 1998: 28). Karena skor total skala dan skor masing-masing faktor berskala ordinal, maka untuk menentukan indeks korelasi 
tersebut digunakan Rank-Order Correlation Coefficient dari Spearman. Adapun rumus dan langkah-langkahnya sama dengan analisis item, hanya saja berbeda dalam variabelnya. Dalam hal ini variabel yang akan dicari indeks korelasinya adalah skor masing-masing faktor atau aspek skala dengan skor total skala.

Tidak ada batasan baku tentang angka minimal yang harus dipenuhi agar suatu skala dianggap valid. Namun jika koefisien validitas itu kurang dari 0,30 biasanya dianggap tidak memuaskan. Cronbach (1970:135 dalam Azwar, 2003:103) mengatakan bahwa jawaban yang paling masuk akal terhadap perta- nyaan mengenai berapa tinggi koefisien validitas yang dianggap memuaskan adalah " Yang tertinggi yang Anda peroleh".

Dari perhitungan diketahui bahwa faktorfaktor atau aspek-aspek pada Skala Relevansi Kurikulum dengan Dunia Kerja memiliki indeks korelasi/ validitas masing-masing sebagai berikut: Tabel 2.

Indeks Korelasi/Validitas Alat Ukur/ Skala Relevansi Kuriku-lum dengan Dunia Kerja

\begin{tabular}{|c|l|c|c|}
\hline No & \multicolumn{1}{|c|}{ Aspek } & $\begin{array}{c}\text { Koefisien } \\
\text { Validitas }\end{array}$ & Keterangan \\
\hline \hline 1 & Tujuan & 0,779 & Validitas tinggi \\
\hline 2 & Isi/Materi & 0,758 & Validitas tinggi \\
\hline 3 & Proses/Strategi & 0,824 & Validitas tinggi \\
\hline
\end{tabular}

Sumber: Hasil Pengolahan Data Penelitian

Dari koefisien validitas tiap aspek dapat dikatakan Skala Relevansi Kurikulum dengan Dunia Kerja memiliki validitas kostruk yang baik.

\section{Analisis Data}

Statistik Deskriptif (Kategorisasi Jenjang)

Statistik deskriptif digunakan untuk mengetahui sebaran subjek berdasarkan karakteristik responden dan profil pandangan alumni terhadap relevansi kurikulum Fakultas Psikologi UIN SGD Bamdung dengan dunia kerja. Untuk itu, digunakan kategorisasi berdasarkan model kategorisasi jenjang (ordinal) yang bertujuan untuk menempatkan individu ke dalam kelompok-kelompok yang terpisah secara berjenjang menurut suatu kontinum berdasarkan atribut yang diukur (Azwar, 2003: 107). Kontinum yang digunakan dalam penelitian ini adalah dari sangat tidak relevan sampai sangat relevan. Adapun norma kategorisasi yang digunakan adalah seperti yang tertera pada tabel 3 .

Tabel 3.

Norma Kategorisasi Jenjang (Ordinal) Pandangan Alumni terhadap Relevansi Kurikulum dengan Dunia Kerja

\begin{tabular}{|c|c|}
\hline Norma & Kategori \\
\hline \hline $\mathrm{X} \leq \mu-1.5 \sigma$ & sangat tidak relevan \\
\hline$\mu-1.5 \sigma<\mathrm{X} \leq \mu-0.5 \sigma$ & tidak relevan \\
\hline $\mathrm{M}-0.5 \sigma<\mathrm{X} \leq \mu+0.5 \sigma$ & cukup relevan \\
\hline $\mathrm{M}+0.5 \sigma<\mathrm{X} \leq \mu+1.5 \sigma$ & relevan \\
\hline$\mu+1.5 \sigma<\mathrm{X}$ & sangat relevan \\
\hline
\end{tabular}

Sumber: Diadaptasi dari Azwar (2003:107)

dengan

$\mu$ : mean teoretis,

$\frac{(\text { skormaks teoretis }- \text { skor min teoretis })}{2}$

$\sigma:$ deviasi standar teoretis,

(skormaks teoretis - skor min teoretis)

6 


\section{Analisis Uji Korelasi}

Seperti telah dikemukakan sebelumnya bahwa sebagai data tambahan akan dilihat juga ada tidaknya kaitan yang signifikan antara karakteristik responden dengan pandangannya terhadap relevansi kurikulum dengan dunia kerja. Untuk mengetahui hal tersebut maka peneliti menggunakan correlational research method. Dalam hal ini variabel-variabel yang akan dicari indeks korelasinya adalah setiap kategori karakteristik responden dengan kategori pandangan responden terhadap relevansi kurikulum dengan dunia kerja. Dengan demikian, karena kedua himpunan atribut bersifat katego rial (skala nominal) maka ukuran korelasi yang digunakan adalah Koefisien Kontingensi $C$. Adapun langkah-langkah penggunaannya sebagai berikut:

a. Atur frekuensi-frekuensi observasi dalam tabel kontingensi $k x r$ dengan $k$ : banyak kategori skor variabel, dan $r$ : banyaknya kategori dari variabel lain.

b. Tentukan frekuensi harapan tiap-tiap sel dengan mengalikan kedua jumlah tepi yang sama-sama dimiliki sel itu dan kemudian membaginya dengan $\mathrm{N}$, yakni jumlah total kasus. Jika lebih dari 20\% diantara sel-sel itu mempunyai frekuensi harapan kurang dari 5, atau jika ada sembarang sel yang mempunyai frekuensi ha rapan kurang dari 1, gabungkan kategori-kategori untuk meningkatkan frekuensi yang tidak memadai.

c. Menghitung harga $\chi^{2}$ dengan rumus:

$$
\chi^{2}=\sum_{i=1}^{r} \sum_{j=1}^{k} \frac{\left(O_{i j} E_{i j}\right)^{2}}{E_{i j}}
$$

d. Dengan harga $\chi^{2}$ di atas hitung harga $\mathrm{C}$ dengan rumus:

$c=\sqrt{\frac{x^{2}}{N+x^{2}}}$

e. Untuk menguji apakah harga observasi $\mathrm{C}$ memberikan petunjuk terdapat asosiasi antara kedua variabel di dalam populasi yang diambil sampelnya, tentukan peluang yang berkaitan dengan harga $\chi^{2}$ dimana $\mathrm{db}=(\mathrm{k}-1)(\mathrm{r}-1)$ dengan tabel C. Jika $p_{\text {value }} \leq \alpha$ tolaklah Ho dan terima $\mathrm{H}_{1}$.

Perhitungan dibantu program SP-SS 11.5 for Windows mengikuti alur Analyze $\rightarrow$ Descriptive Statistics $\rightarrow$ Crostab $\rightarrow$ Insert data $\rightarrow$ Contingency Coefficient.

\section{Hasil Penelitian}

Berdasarkan skor subjek pada Skala Relevansi Kurikulum dengan Dunia Kerja diketahui pandangan alumni terhadap relevansi kurikulum dengan dunia kerja sebagai berikut. Tabel 4.

Sebaran Alumni Berdasarkan Pandangannya terhadap Relevansi Kurikulum dengan Dunia Kerja

(Digali dengan Skala)

\begin{tabular}{|l|c|c|}
\hline \multicolumn{1}{|c|}{ Kategori } & Jmlah & Persentase \\
\hline \hline Sangat Tidak Relevan & 0 & $0 \%$ \\
\hline Tidak Relevan & 7 & $22.58 \%$ \\
\hline Cukup Relevan & 18 & $58,06 \%$ \\
\hline Relevan & 6 & $19.36 \%$ \\
\hline Sangat Relevan & 0 & $0 \%$ \\
\hline Jumlah & 31 & $100 \%$ \\
\hline
\end{tabular}

Sumber: Hasil Pengolahan Data Penelitian

Hasil ini diperkuat oleh hasil angket data penunjang yang menggali pandangan alumni tentang relevansi kurikulum dengan dunia kerja dengan pertanyaan tunggal yang 
hasilnya tidak terlalu jauh berbeda dengan yang digali melalui skala seperti pada tabel 5 .

Tabel 5.

Sebaran Alumni Berdasarkan Pandangannya terhadap Relevansi Kurikulum dengan Dunia Kerja

(Digali dengan Angket)

\begin{tabular}{|l|c|c|}
\hline \multicolumn{1}{|c|}{ Kategori } & Jumlah & Persentase \\
\hline \hline Sangat Tidak Relevan & 0 & $0 \%$ \\
\hline Tidak Relevan & 7 & $22.58 \%$ \\
\hline Cukup Relevan & 17 & $54,84 \%$ \\
\hline Relevan & 6 & $19.36 \%$ \\
\hline Sangat Relevan & 1 & $03.23 \%$ \\
\hline Jumlah & 31 & $100 \%$ \\
\hline
\end{tabular}

Sumber: Hasil Pengolahan Data Penelitian

Penggalian melalui skala selain dapat melihat pandangan alumni pada keseluruhan aspek kurikulum juga dapat melihat per aspeknya. Bila kita lihat sebaran skor subjek pada ketiga komponen kurikulum, umumnya alumni menunjukkan ketidakpuasan atau menganggap ketidakrelevanan kurikulum terutama pada komponen atau aspek proses yang berkaitan dengan penyediaan sarana dan prasarana yang belum memadai. Hal itu ditunjukkan pada tabel 6. Hal ini dapat difahami bila mengingat kondisi Fakultas Psikologi UIN SGD Bandung yang memang relatif baru dan masih perlu melakukan pembenahan di berbagai lini. Namun hal ini tetap perlu mendapat perhatian segera dari para pengambil kebijakan karena tersedia-tidaknya sarana dan prasarana dalam proses pembelajaran, termasuk penyediaan SDM dosen yang memadai, sangat dirasakan langsung dampaknya oleh para alumni sejak di bangku kuliah. Sementara pada kedua aspek lainnya yaitu tujuan dan materi kurikulum, alumni umumnya masih menganggap cukup relevan.

Tabel 6.

Rata-Rata Skor Subjek pada Setiap Aspek Kurikulum (Skala) dan Rata - Rata Total Skornya

\begin{tabular}{|l|c|}
\hline \multicolumn{1}{|c|}{ Komponen/Aspek Kurikulum } & $\begin{array}{c}\text { Rata-Rata Skor }(\mu) \\
\text { Subjek }\end{array}$ \\
\hline \hline 1. Tujuan & 31,13 \\
\hline 2. Isi/ Materi & 31,10 \\
\hline 3. Proses & 26,61 \\
\hline $\begin{array}{l}\text { Keseluruhan Aspek } \\
\text { (Skor Total Skala) }\end{array}$ & 88,84 \\
\hline
\end{tabular}

Sumber: Hasil Pengolahan Data Penelitian

Untuk pandangan terhadap relevansi kurikulum dengan dunia kerja tampak bahwa hampir di semua aspek karakteristik responden, menunjukkan sebagian besar ada pada kategori cukup relevan. Meskipun secara statistik seperti tampak pada tabel 7 beberapa karakteristik menunjukkan nilai koefisien rendah, namun dengan nilai peluang $\left(p_{v}\right)$ yang lebih tinggi dari tingkat signifikansi ( $\alpha=$ $0,05)$ maka hubungan tersebut dianggap tidak berarti. Tetapi bila sebaliknya $p_{v}>\alpha$ maka terima $\mathrm{Ho}$, tolak $\mathrm{H}_{1}$, artinya tidak terdapat hubungan antara pandangan responden dengan relevansi kurikulum dengan dunia kerja. 


\section{Tabel 7.}

Hubungan antara Karakteristik Responden dengan Pandangannya terhadap Relevansi Kurikulum dengan Dunia Kerja

\begin{tabular}{|c|l|c|c|c|}
\hline No. & $\begin{array}{l}\text { Karakteristik } \\
\text { Responden }\end{array}$ & Probabilitas & $\begin{array}{c}\text { Koefisien } \\
\text { Kontingensi }\end{array}$ & Kesimpulan \\
\hline \hline 1 & $\begin{array}{l}\text { Jenis } \\
\text { Kelamin }\end{array}$ & 0,221 & 0,298 & $\begin{array}{l}\text { Tidak ada } \\
\text { hubungan }\end{array}$ \\
\hline 2 & Usia & 0,972 & 0,043 & $\begin{array}{l}\text { Tidak ada } \\
\text { hubungan }\end{array}$ \\
\hline 3 & $\begin{array}{l}\text { Status } \\
\text { Marital }\end{array}$ & 0,076 & 0,377 & $\begin{array}{l}\text { Tidak ada } \\
\text { hubungan }\end{array}$ \\
\hline 4 & $\begin{array}{l}\text { Asal Sekolah } \\
\text { Menengah }\end{array}$ & 0,287 & 0,273 & $\begin{array}{l}\text { Tidak ada } \\
\text { hubungan }\end{array}$ \\
\hline 5 & $\begin{array}{l}\text { Tahun } \\
\text { Masuk/ } \\
\text { Angkatan }\end{array}$ & 0,365 & 0,247 & $\begin{array}{c}\text { Tidak ada } \\
\text { hubungan }\end{array}$ \\
\hline 6 & Tahun Lulus & 0,482 & 0,317 & $\begin{array}{l}\text { Tidak ada } \\
\text { hubungan }\end{array}$ \\
\hline 7 & Yudisium & 0,217 & 0,396 & $\begin{array}{l}\text { Tidak ada } \\
\text { hubungan }\end{array}$ \\
\hline 8 & $\begin{array}{l}\text { Lamanya } \\
\text { Kuliah }\end{array}$ & 0,468 & 0,392 & $\begin{array}{l}\text { Tidak ada } \\
\text { hubungan }\end{array}$ \\
\hline 9 & $\begin{array}{l}\text { Penyelesaian } \\
\text { Skripsi }\end{array}$ & 0,892 & 0,262 & $\begin{array}{l}\text { Tidak ada } \\
\text { hubungan }\end{array}$ \\
\hline 10 & $\begin{array}{l}\text { Pendidikan } \\
\text { Terakhir }\end{array}$ & 0,170 & $\begin{array}{l}\text { Tidak ada } \\
\text { hubungan }\end{array}$ \\
\hline
\end{tabular}

Sumber: Hasil Pengolahan Data Penelitian pada Lampiran (2008)

Kriteria uji: Jika probabilitas $\left(p_{v}\right)$ lebih kecil dari tingkat signifikansi $(\alpha=0,05)$ maka tolak Ho, terima $\mathrm{H}_{1}$. Artinya terdapat hubungan antara pandangan responden terhadap relevansi kurikulum dengan dunia kerja.

\section{Simpulan dan Saran}

Simpulan

Berdasarkan data dan pembahasannya dapat ditarik kesimpulan bahwa kurikulum Fakultas Psikologi UIN SGD Bandung masih dipandang cukup relevan hingga relevan oleh sebagian besar alumni. Hal ini diperkuat dengan masih relevannya bidang pekerjaan sebagian besar alumni dengan profesi psikologi. Namun demikian, semua responden/alumni tetap menghendaki adanya perubahan dan perbaikan di semua komponen kurikulum agar lebih sesuai dengan tuntutan kebutuhan masyarakat, terutama lebih aplikatif dan relevan dengan tuntutan dunia kerja, sehingga lulusannya lebih kompeten dan memiliki daya saing tinggi serta siap pakai oleh para pengguna lulusan (user).

Saran

Berdasarkan simpulan di atas maka diajukan saran-saran sebagai berikut:

1. Dengan memperhatikan saran dan masukan dari alumni, perlu kiranya rumusan kurikulum Fakultas Psikologi UIN SGD Bandung senantiasa dievaluasi dan disempurnakan agar relevan dengan perkembangan zaman dan kebutuhan masyarakat dan memiliki relevansi yang tinggi dengan tuntutan dunia kerja. Untuk itu diperlukan tim perancang yang memahami konsep maupun praktek pengembangan kurikurikulum secara profesional, khususnya untuk program studi psikologi.

2. Agar diperoleh umpan balik yang lebih menyeluruh, untuk penelitian lanjut perlu kiranya melibatkan stakeholders dan pengguna lulusan psikologi (user) serta jumlah responden alumni yang lebih banyak dan representatif sehingga dapat memetakan keberadaan dan gambaran alumni secara lebih menyeluruh.

\section{Daftar Pustaka}

Arikunto, Suharsimi. (1998). Prosedur Penelitian: Suatu Pendekatan Praktek. Jakarta: PT. Rineka Cipta.

Azwar, Saepudin. (2003). Penyusunan Skala Psikologi. Yogyakarta: Pustaka Pelajar.

Bisri, Cik H, dkk. Profil Alumni Fakultas Ushuluddin IAIN Tahun 1991-200. Laporan Penelitian. Bandung: Lembaga Penelitian IAIN SGD. 
Djatmika, Ratna. (1998). Pelatihan Penyusunan dan Pengujian Alat Ukur Ilmu Sosial. Jatinangor: Fakultas Psikologi Universitas Padjadjaran.

Friedenberg, Lisa. (1995). Psychological Testing: Design, Analysis, and Use. USA: Allyn \& Bacon.

Fakultas Psikologi Unair. (2001). Sinopsis Hasil Diskusil Lokakarya Pendidikan Psikologi di Indonesia. Surabaya: Kolokium Psikologi Indonesia.

Fakultas Psikologi UIN SGD. (2007). Kurikulum Fakultas Psikologi UIN SGD, Berdasarkan Kolokium Psikologi Tahun 2007. Bandung: Gunung Djati.

Fakultas Tarbiyah IAIN SGD. (2005). Panduan Teknis Kegiatan Akademik: Jurusan/Program Studi/ Diploma. Bandung : Fakultas Tarbiyah IAIN SGD

Graziano, M.A.\& Raulin, M.L. (2000). Methods Research: A Process of Inquiry, Fourth Edition. USA: Allyn \& Bacon.

Hadi, Sutrisno. (1994). Metodology Research. Jilid 1. Yogyakarta : Andi Offset.

Hamalik, Oemar. (1986) Evaluasi Kurikulum. Bandung: Pustaka Martiana. (1995). Kurikulum dan Pembelajaran. Jakarta: Bumi Aksara. (2007). Manajemen Pengembangan Kurikulum. Bandung: PT Remaja Rosdakarya.

Kerlinger, F.N. (2004). Asas-Asas Penelitian Behavioral. Edisi Ketiga. (Alih Bahasa oleh Dra. Landung R. Simatupang). Yogyakarta: Gadjah Mada University Press.

Kumar, R. (1999). Research Methodology: A Step-by-step Guide for Beginners. London: Sage Publication.

Mulyana, E. (2006). Kurikulum yang Disempurnakan: pengembangan standar kompetensi dan kompetensi dasar. Bandung: PT Remaja Rosdakarya.

Nasution, S. (1993). Pengembangan Kurikulum. Bandung: Citra Aditya Bakti.

(1995). Asas-asas Kurikulum. Jakarta: Bumi Aksara.

Neuman, W.L. (2000). Social Research Methods : Qualitative and Quantitative Approaches. Boston: Allyn and Bacon.

Oliva, Peter F. (1992). Developing the Curiculum. Third Edition. New York: HarperCollins Publisher.
Sanjaya, Wina. (2008). Kurikulum dan Pembelajaran: teori dan praktik pengembangan kurikulum tingkat satuan pendidikan (KTSP). Jakarta: Kencana

Schubert, W.H. (1987). Curiculum: perspective, paradigm, and Possibility. Chicago: Macmillan Publishing Company.

Shaughnessy J. \& Zechmeister, Eugene B. 1994. Research Methods in Psychology, Third Edition. Singapore: McGrawHill.

Siegel, Sidney. 1997. Statistik Nonparametrik untuk Ilmu-ilmu Sosial. Terjemahan Zanzawi Suyuti \& Landung Simatupang. Jakarta: Gramedia Pustaka.

Subino. 1987. Konstruksi dan Analisis Tes. Jakarta: Departemen Pendidikan dan Kebudayaan.

Sudrajat, M. 2000. Serial Pengenalan Dasardasar Statistika Terapan: Statistika Sosial. Jatinangor: Fakultas Pertanian Universitas Padjadjaran.

Sukmadinata, Nana S. (2008). Pengembangan Kurikulum: teori dan praktek. Bandung: PT Remaja Rosdakarya.

Team Penyusun Kurikulum. (2007). Kurikulum: berdasarkan kolokium psikologi tahun 2007. Bandung: Fakultas Psikologi Universitas Islam Negeri Sunan Gunung Djati Bandung.

Zais, Robert S. (1976). Curiculum: priciple and foundation. New York: Harper \& Row, Publisher, Inc.

Wahana Komputer. (2002). 10 Model Penelitian dan Pengolahannya dengan SPSS 10.01. Yogyakarta: Andi 